\title{
Newly observed peroxides and the water effect on the formation and removal of hydroxyalkyl hydroperoxides in the ozonolysis of isoprene
}

\author{
D. Huang, Z. M. Chen, Y. Zhao, and H. Liang
}

State Key Laboratory of Environmental Simulation and Pollution Control, College of Environmental Sciences and Engineering, Peking University, Beijing 100871, China

Correspondence to: Z. M. Chen (zmchen@pku.edu.cn)

Received: 5 January 2013 - Published in Atmos. Chem. Phys. Discuss.: 25 February 2013

Revised: 4 May 2013 - Accepted: 15 May 2013 - Published: 12 June 2013

\begin{abstract}
The ozonolysis of alkenes is considered to be an important source of atmospheric peroxides, which serve as oxidants, reservoirs of $\mathrm{HO}_{\mathrm{x}}$ radicals, and components of secondary organic aerosols (SOAs). Recent laboratory investigations of this reaction identified hydrogen peroxide $\left(\mathrm{H}_{2} \mathrm{O}_{2}\right)$ and hydroxymethyl hydroperoxide (HMHP) in ozonolysis of isoprene. Although larger hydroxyalkyl hydroperoxides (HAHPs) were also expected, their presence is not currently supported by experimental evidence. In the present study, we investigated the formation of peroxides in the gas phase ozonolysis of isoprene at various relative humidities on a time scale of tens of seconds, using a quartz flow tube reactor coupled with the online detection of peroxides. We detected a variety of conventional peroxides, including $\mathrm{H}_{2} \mathrm{O}_{2}$, HMHP, methyl hydroperoxide, bis-hydroxymethyl hydroperoxide, and ethyl hydroperoxide, and interestingly found three unknown peroxides. The molar yields of the conventional peroxides fell within the range of values provided in the literature. The three unknown peroxides had a combined molar yield of $\sim 30 \%$ at $5 \%$ relative humidity (RH), which was comparable with that of the conventional peroxides. Unlike $\mathrm{H}_{2} \mathrm{O}_{2}$ and HMHP, the molar yields of these three unknown peroxides were inversely related to the $\mathrm{RH}$. On the basis of experimental kinetic and box model analysis, we tentatively assigned these unknown peroxides to $\mathrm{C} 2-\mathrm{C} 4 \mathrm{HAHPs}$, which are produced by the reactions of different Criegee intermediates with water. Our study provides experimental evidence for the formation of large HAHPs in the ozonolysis of isoprene (one of the alkenes). These large HAHPs have a sufficiently long lifetime, estimated as tens of minutes, which al-
\end{abstract}

lows them to become involved in atmospheric chemical processes, e.g., SOA formation and radical recycling.

\section{Introduction}

Peroxides, including hydrogen peroxide and organic peroxides, are considered to be important trace compounds in the atmosphere due to their multiple roles as oxidants (Calvert et al., 1985) and reservoirs of radicals $\left(\mathrm{HO}_{\mathrm{x}}, \mathrm{RO}_{2}\right)$ (Wallington and Japar, 1990; Lightfoot et al., 1991; Vaghjiani and Ravishankara, 1990; Hatakeyama et al., 1991; Atkinson et al., 1992; Spittler et al., 2000; Ravetta et al., 2001). Furthermore, they can harm vegetation (Hewitt et al., 1990; Pellinen et al., 2002) and are known to be important components of secondary organic aerosols (SOAs) (Bonn et al., 2004; Docherty et al., 2005; Hallquist et al., 2009; Chen et al., 2011). In the laboratory, organic peroxides are known to be major products of the photooxidation of isoprene by the $\mathrm{OH}$ radical under $\mathrm{NO}_{\mathrm{x}}$-free conditions (Miyoshi et al., 1994; Paulot et al., 2009). Using the iodometric spectrophotometric method, Surratt et al. (2006) quantitatively reported that total organic peroxides account for $25-60 \%$ of SOA mass formed from the photooxidation of isoprene. Some model results suggest that organic peroxides are even more important than carboxylic acids as SOA contributors (Bonn et al., 2004). Kroll et al. (2006) suggested that the decrease in SOA mass during the photooxidation of isoprene may be attributed to the chemical reactions of organic peroxides. There are no known primary sources of peroxides. An important pathway for their 
formation is considered to be the bimolecular reaction between $\mathrm{RO}_{2}$ and $\mathrm{HO}_{2}$ radicals, while $\mathrm{RO}_{2}$ radicals are mainly formed from the $\mathrm{OH}$ radical-initiated photooxidation of alkanes and alkenes under low $\mathrm{NO}_{\mathrm{x}}$ conditions (e.g., Atkinson et al., 2006). Another pathway for the formation of hydroperoxides is the ozonolysis of alkenes (e.g., Becker et al., 1990; Hewitt et al., 1990; Gäb et al., 1995; Neeb et al., 1997; Sauer et al., 1999; Lee et al., 2000; Tobia and Ziemann, 2001). A peak in the concentration of peroxides was found at night in field measurements (Hua et al., 2008), providing evidence for the important contribution from the ozonolysis of alkenes.

Scheme 1 illustrates a summary of the major known steps in the ozonolysis of alkenes. The formation of peroxides is related to the reactions of Criegee intermediates, i.e., isomerization (R3b), reaction with water (R4a1), and reaction with organic acid (R4a2); whereas the decomposition of peroxides follows pathways of R4b1, R4a11, R4a12, R4a13, and R4a14. Considering the ubiquity of water molecules in the atmosphere, water plays a principal role in hydroxyalkyl hydroperoxide (HAHP) formation via the reaction of R4a1 (Gäb et al., 1985; Hatakeyama and Akimoto, 1994; Ryzhkov and Ariya, 2004, 2006). In theoretical studies, Crehuet et al. (2001) suggested that the $\mathrm{CH}_{2} \mathrm{OO}$ biradical, the simplest Criegee intermediate, would have a two-step reaction with $\mathrm{H}_{2} \mathrm{O}$, first generating HMHP and then decomposing. Aplincourt and Anglada (2003a) showed that the most favourable pathway for the reaction of water and the isoprene Criegee intermediate is the formation of HAHP. The HAHP would decompose into the corresponding carbonyl and $\mathrm{H}_{2} \mathrm{O}_{2}$ (Atkinson and Arey, 2003). Very recently, Welz et al. (2012) directly determined unexpectedly large rate constants for the reactions of the Criegee intermediate with $\mathrm{SO}_{2}$ and $\mathrm{NO}_{2}$, indicating that Criegee intermediates may be important oxidants for $\mathrm{SO}_{2}$ and $\mathrm{NO}_{2}$. Vereecken et al. (2012) presented a series of loss pathways for the stabilised Criegee intermediate, and found that its loss was dominated by its reaction with $\mathrm{H}_{2} \mathrm{O}, \mathrm{NO}_{2}$, and $\mathrm{SO}_{2}$, for which $\mathrm{H}_{2} \mathrm{O}$ is the most efficient scavenger.

There have been only a few chamber studies focusing on hydrogen peroxide and the $\mathrm{C} 1-\mathrm{C} 3$ hydroperoxide formation in the ozonolysis of alkenes (Gäb et al., 1985, 1995; Hewitt and Kok, 1991; Horie et al., 1994; Neeb et al., 1997; Sauer et al., 1999; Hasson et al., 2001a, b). However, to date, the identified peroxides are mostly limited to $\mathrm{H}_{2} \mathrm{O}_{2}$ and HMHP. The larger HAHPs have been speculated in laboratory studies, although their possible decomposition products such as $\mathrm{H}_{2} \mathrm{O}_{2}$, carbonyls, and organic acids have been quantitatively observed. Moreover, there is large uncertainty for the $\mathrm{H}_{2} \mathrm{O}_{2}$ and HMHP yields obtained in chamber experiments, which usually last for tens of minutes to several hours of reaction time, due to the decomposition and wall losses of the highly reactive peroxides. In addition, most experiments have been performed at either a low or high relative humidity rather than at various relative humidity values.
In the present study, we detect more peroxide types in the reaction of ozone and isoprene in the gas phase to evaluate the reaction mechanism of Criegee intermediates with water, and we study the peroxide yield dependence on the relative humidity. We conduct simulations for the ozonolysis of isoprene in a quartz flow tube reactor with a reaction time of tens of seconds at ten different relative humidities, using an online HPLC detection for the peroxides. A variety of peroxides have been identified and quantified or semi-quantified, in particular organic peroxides. A box model is used to simulate the HAHPs' formation process, and simultaneously to study the effect of water on the formation and removal of HAHPs.

\section{Experimental}

\subsection{Chemicals}

Isoprene (Fluka, 99.5\%), ultrapure water (18 M $\Omega$, Millipore), acetonitrile (Tedia, spectroscopically pure, $\geq 99.9 \%$ ), $\mathrm{N}_{2} \quad(\geq 99.999 \%$, Beijing Haikeyuanchang Practical Gas Company Limited, Beijing, China), and $\mathrm{O}_{2}(\geq 99.999 \%$, Beijing Haikeyuanchang Practical Gas Company Limited, Beijing, China) were used as received. The source and purity of authentic standards for synthesising peroxides are: $\mathrm{H}_{2} \mathrm{O}_{2}$ (Acros, 35 wt. \%), formaldehyde (Riedel-delaen, $36.5 \mathrm{wt} . \%$ ), acetaldehyde (Amethyst, $40 \mathrm{wt} . \%$ ), glycoaldehyde (Aldrich, crystalline), propanal (Fluka, 99.7\%), glyoxal (Sigma-Aldrich, 40 wt. \%), formic acid (Alfa Aesar, 97\%), acetic acid (Alfa Aesar, 99.9985\%), glycolic acid (SigmaAldrich, 99\%), propionic acid (Alfa Aesar, 99\%), acetone (Fluka, 99.7\%), hydroxyacetone (Fluka, 90\%), 2-Br-ethanol (Alfa Aesar, 97\%), 3-Br-1-proponol (Alfa Aesar, 97+\%), and 1-Br-2-proponol (Aldrich, $70 \%$ ).

\subsection{Apparatus and procedure}

A flow tube reactor $(100 \mathrm{~cm}$ length, $5 \mathrm{~cm}$ inner diameter, quartz wall) equipped with a water jacket for temperature control was employed for performing ozonolysis experiments in the dark. Figure 1 provides the overview of the apparatus. The temperature of the reactor was controlled to $25 \pm 0.5^{\circ} \mathrm{C} . \mathrm{O}_{3}$ was generated by the UV irradiation of a $0.1 \mathrm{~L} \mathrm{~min}^{-1}$ flow of $\mathrm{O}_{2}$, and the concentration was controlled by the light intensity. Isoprene stock gas was prepared by injecting $4.0 \mu \mathrm{L}$ liquid isoprene into an evacuated steel canister (15.0 L, Entech Instrument), followed by the addition of $\mathrm{N}_{2}$ to the canister to a pressure of $30 \mathrm{psi}$. The isoprene concentration in the canister was $20.6 \mathrm{ppmv}$. Through a mass flow controller (MFC), the stock isoprene gas was introduced into the flow reactor from the canister. Water vapour was generated by passing $\mathrm{N}_{2}$ through a glass tube containing two floors of carborundum disc submerged in ultrapure water (18 $\mathrm{M} \Omega$ ). There were two gas entrances on the reactor, and the flow through each entrance was $1.0 \mathrm{~L} \mathrm{~min}^{-1}$. One entrance 


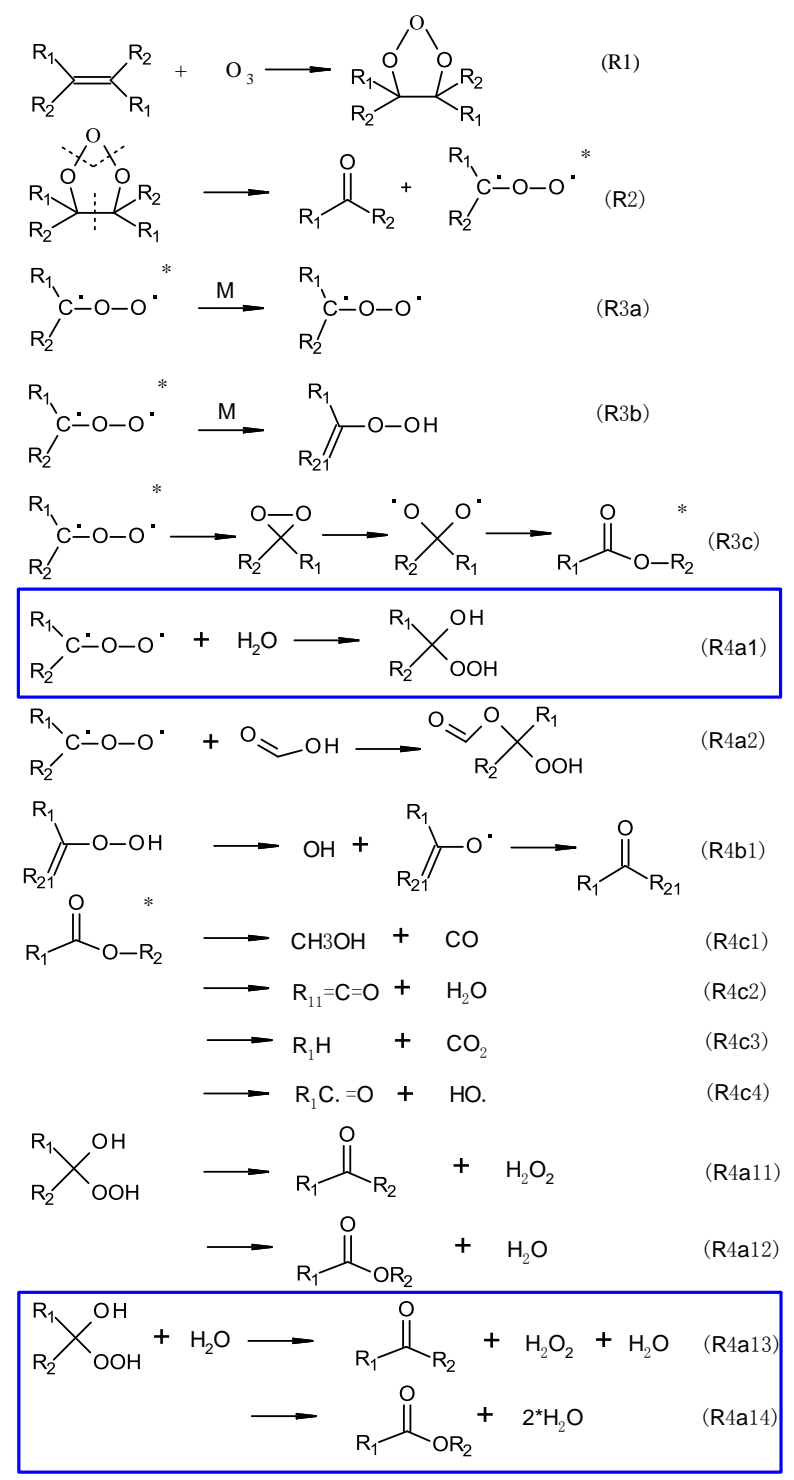

Scheme 1. The major steps for the ozonolysis of alkenes in the gas phase. The reactions in the blue box are related to the water effect on the formation and removal of HAHPs.

introduced a mixture of isoprene, dry $\mathrm{N}_{2}$, and wet/dry $\mathrm{N}_{2}$. The other introduced a mixture of $\mathrm{O}_{3}, \mathrm{O}_{2}$, and wet/dry $\mathrm{N}_{2}$. The residence time of the gases was estimated to be $68 \mathrm{~s}$ with a total flow of $2.0 \mathrm{~L} \mathrm{~min}^{-1}$. The final ratio of $\mathrm{N}_{2}$ to $\mathrm{O}_{2}$ was $80 \%: 20 \%$. The initial concentrations of isoprene $\left(\mathrm{C}_{\mathrm{ISO}}\right)$ and $\mathrm{O}_{3}\left(\mathrm{C}_{\mathrm{O}_{3}}\right)$ in the reactor were $290 \mathrm{ppbv}$ and 80 ppmv, respectively. The ratio of $\mathrm{C}_{\mathrm{O}_{3}}$ to $\mathrm{C}_{\text {ISO }}$ was about 300 , which is similar to the ratio in the real atmosphere. After each experiment, the reactor was rinsed out twice with water and was dried with $\mathrm{N}_{2}$.

It is worth noting that, using the flow tube reactor, the reaction time was $68 \mathrm{~s}$ although each experiment lasted for

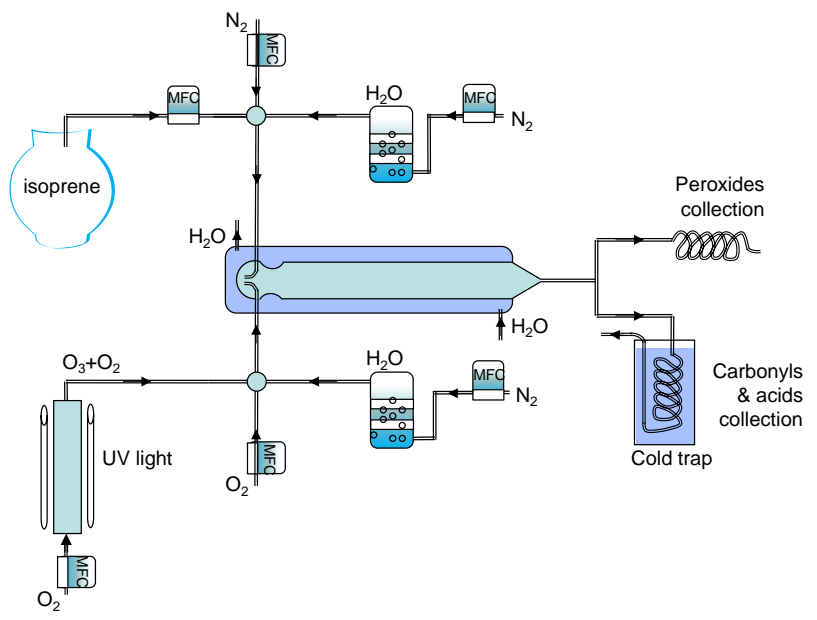

Fig. 1. Schematic diagram of the flow tube reactor and the gas path system. MFC: mass flow controller.

several hours. The reactants and nitrogen plus oxygen were constantly added to the reactor; then an hour later, the concentrations of the products become constant. Next, the products were collected and detected either online or offline. We ensured that the reactants and the products mixture continuously contacted the reactor wall for one hour, to age the reactor wall and thus decrease the wall effect on the products.

\subsection{Products analysis}

The concentrations of $\mathrm{O}_{3}$ and the major products, including peroxides, carbonyl compounds, and organic acids, were determined using methods described in our previous work (Wang et al., 2009; Hua et al., 2008; Huang et al., 2011). Generally, peroxide compounds were collected in a coil collector with an $\mathrm{H}_{3} \mathrm{PO}_{4}$ solution $(\mathrm{pH} 3.5)$ and were online analysed by high performance liquid chromatography (HPLC) (Agilent 1100, USA) coupled with post-column derivatization. In this latter step, the peroxides oxidised phydroxyphenylacetic acid to produce a fluorescent dimer in a reaction catalysed by hemin. The reaction mixtures were collected for $1 \mathrm{~min}$ at a time. We used the reaction between $\mathrm{H}_{2} \mathrm{O}_{2}$ and $\mathrm{HCHO}$, both of which are the important products in the ozonolysis of isoprene, to probe the possibility of a chemical reaction occurring in the scrubbing $\mathrm{H}_{3} \mathrm{PO}_{4}$ solution. We mixed $10^{-6} \mathrm{M} \mathrm{H}_{2} \mathrm{O}_{2}$ with $10^{-5} \mathrm{M} \mathrm{HCHO}$ in $\mathrm{H}_{3} \mathrm{PO}_{4}$ solution, and we did not detect HMHP in the mixture $30 \mathrm{~min}$ later. This result implied that the chemistry occurring in the scrubbing solution inside the coil collector was unimportant. The samples for determining the carbonyls were collected using the cold trap method, in which a $2.0 \mathrm{~L} \mathrm{~min}^{-1}$ gas mixture from the outlet of the reactor passed through a Horibe tube in a cold trap of ethanol-liquid nitrogen at about $-90^{\circ} \mathrm{C}$. In our experiments, the "Horibe tube" was made of three glass components: an inlet main tube ( $25 \mathrm{~cm}$ length, $4 \mathrm{~cm}$ O.D.), a coil (4-6 laps, $1 \mathrm{~cm}$ O.D.) linked to and around the main 
tube, and an outlet carborundum disc. After the sample was collected for $30 \mathrm{~min}$, the Horibe tube was removed from the cold trap, and immediately $10 \mathrm{~mL}$ acetonitrile was used to strip the tube inside. In this process, $2 \mathrm{~mL}$ stripping solution was mixed with $2 \mathrm{~mL} \mathrm{2,4-dinitrophenyhydrazine} \mathrm{(DNPH)-}$ acetonitrile solution for $24 \mathrm{~h}$ derivatization, and the derivatization solution was analysed by HPLC with UV detection (Agilent 1100, USA). The samples for the organic acids were also collected using the cold trap method, and water was used to strip the Horibe tube. The $2 \mathrm{~mL}$ stripping solution was immediately analysed with ion chromatography (DIONEX 2650, USA) and an ED50 conductivity detector. During the collection process, $\mathrm{O}_{3}$ and isoprene could not be frozen in the tube - only the reaction products were captured by the cold tube. The reaction rate of $\mathrm{O}_{3}$ and isoprene at $-90^{\circ} \mathrm{C}$ was much lower than it was at $25^{\circ} \mathrm{C}$. We think the reactions during the collection process were unimportant to the formation of the observed products.

\subsection{Control experiments: $\mathrm{H}_{2} \mathrm{O}_{2}$ background and peroxide wall loss}

Blank runs were performed to investigate the potential $\mathrm{H}_{2} \mathrm{O}_{2}$ produced during the process of $\mathrm{O}_{3}$ generation by UV irradiation of oxygen and trace water; that is, we passed the mixture of $\mathrm{O}_{3}+\mathrm{N}_{2}+\mathrm{O}_{2}$ through the reactor in the absence of isoprene. The measured $\mathrm{H}_{2} \mathrm{O}_{2}$ was considered to be the blank background that should be subtracted from the $\mathrm{H}_{2} \mathrm{O}_{2}$ observed in the isoprene ozonolysis experiment.

The wall losses of the reactants $\left(\mathrm{O}_{3}\right.$ and isoprene) were negligible; however, the wall losses of the oxygenated products were inevitable, especially under high $\mathrm{RH}$ conditions. A series of peroxides, including $\mathrm{H}_{2} \mathrm{O}_{2}$, HMHP, 1-hydroxyethyl hydroperoxide (1-HEHP), peroxyacetic acid (PAA), and perpropionic acid (PPA), were selected as representatives to determine the wall losses of the oxygenated products. HMHP and 1-HEHP are proxies for 1-hydroxyl hydroperoxides, and PAA and PPA are proxies for peroxy acids. Peroxide gas with a certain concentration was obtained by passing $100 \mathrm{~mL} \mathrm{~N}_{2}$ through a diffusion tube containing a peroxide solution. The peroxide gas was then introduced into the flow tube together with water vapour and $\mathrm{N}_{2}$ plus $\mathrm{O}_{2}$, which resulted in a total flow of $2.0 \mathrm{~L} \mathrm{~min}^{-1}$ and a peroxide concentration close to that observed in the ozonolysis experiment. The wall losses of the peroxides, which were a function of $\mathrm{RH}$, were determined as the difference between the peroxide concentrations of the inlet and the outlet of the reactor after $60 \mathrm{~min}$ of peroxide passing (at which time the peroxide concentrations became constant). These losses were represented by the ratio $\left(\mathrm{C}_{\mathrm{IN}}-\mathrm{C}_{\mathrm{OUT}}\right) / \mathrm{C}_{\mathrm{IN}}$. In addition, we adjusted the total gas flow passing through the reactor to reach variable gas residence times of $45 \mathrm{~s}$ at $3.0 \mathrm{~L} \mathrm{~min}^{-1}, 68 \mathrm{~s}$ at $2.0 \mathrm{~L} \mathrm{~min}^{-1}, 135 \mathrm{~s}$ at $1.0 \mathrm{~L} \mathrm{~min}^{-1}$, and $270 \mathrm{~s}$ at $0.5 \mathrm{~L} \mathrm{~min}^{-1}$, respectively. We then obtained the variation profiles of the wall loss with residence time for $\mathrm{H}_{2} \mathrm{O}_{2}$ and $\mathrm{HMHP}$ at $5 \% \mathrm{RH}$.

\subsection{Modelling methodology}

A box model coupled with a near-explicit mechanism of ozonolysis of isoprene under $\mathrm{NO}_{\mathrm{x}}$-free conditions, which was extracted from the Master Chemical Mechanism version 3.2 (MCM v3.2) (website: http://mcm.leeds.ac.uk/MCM; Jenkin et al., 1997; Saunders et al., 2003), was set up to simulate the reaction processes of the $\mathrm{O}_{3}$-initiated oxidation of isoprene occurring in the flow tube reactor. We expanded the extracted mechanism to include a dozen reactions for the formation of hydroxyalkyl hydroperoxides (HAHPs) via reactions between the gaseous water and Criegee intermediates and the reactions of the water-assisted decomposition of HAHPs. In this model, we tentatively investigated the water effect on the products' formation and removal.

\section{Results and discussion}

\subsection{Background and wall loss quantification}

In the $\mathrm{H}_{2} \mathrm{O}_{2}$ background experiment, the measured $\mathrm{H}_{2} \mathrm{O}_{2}$ concentration at the outlet of the reactor became constant after the $\mathrm{O}_{3}$-containing gas passed through the reactor for about 30 min. Generally, the $\mathrm{H}_{2} \mathrm{O}_{2}$ background was less than $5 \%$ of the formed $\mathrm{H}_{2} \mathrm{O}_{2}$ from the isoprene ozonolysis. Figure 2 shows the wall loss profiles of several peroxides with increasing RH. For $\mathrm{H}_{2} \mathrm{O}_{2}$, the RH dependence of the wall loss was a "V-shaped" curve, with its lowest level (0.02) occurring at $30 \% \mathrm{RH}$, and its highest level (0.11) occurring at $80 \% \mathrm{RH}$. For 1-hydroxyl hydroperoxides, HMHP and 1-HEHP had a wall loss curve similar to that of $\mathrm{H}_{2} \mathrm{O}_{2}$ but with a higher loss fraction. The wall loss of peroxy acids, however, steadily increased with increasing RH, and the highest value was 0.21 at $80 \% \mathrm{RH}$. In general for the wall loss of peroxides, HMHP seemed to present an upper limit, while $\mathrm{H}_{2} \mathrm{O}_{2}$ showed the lower limit. In this study, the background of $\mathrm{H}_{2} \mathrm{O}_{2}$ and the wall loss of $\mathrm{H}_{2} \mathrm{O}_{2}$ and organic peroxides were considered in the data analysis.

In addition, we considered the possibility of peroxides formation on the walls. After each experiment, the reactor wall was washed with water, and then the eluate was collected for a peroxides analysis to detect if large quantities of peroxides were present. However, only $\mathrm{H}_{2} \mathrm{O}_{2}$ and $\mathrm{HMHP}$ were detected in the eluate. Thus, we believe that formation on the walls was an unimportant pathway for the more complicated peroxides.

\subsection{Conventional products: peroxides, carbonyls and organic acids}

This study identified a number of conventional hydroperoxides, which have been generally reported in the related literature, as products in the ozonolysis of isoprene. They include hydrogen peroxide $\left(\mathrm{H}_{2} \mathrm{O}_{2}\right)$, hydroxymethyl hydroperoxide (HMHP), bis-hydroxymethyl hydroperoxide 


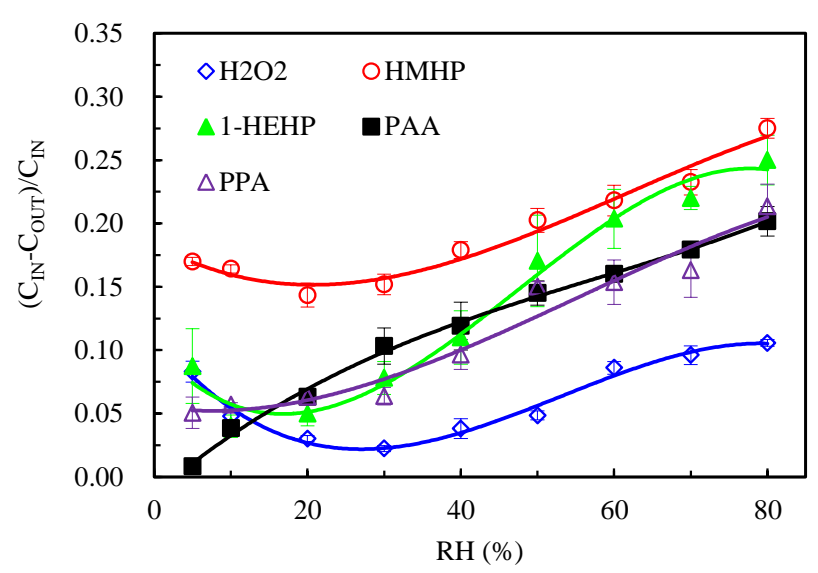

Fig. 2. The variation of peroxides wall losses, $\left(\mathrm{C}_{\mathrm{IN}}-\mathrm{C}_{\mathrm{OUT}}\right) / \mathrm{C}_{\mathrm{IN}}$, with increasing relative humidity $(\mathrm{RH}) . \mathrm{H}_{2} \mathrm{O}_{2}$ : hydrogen peroxide; HMHP: hydroxymethyl hydroperoxide; 1-HEHP: 1-hydroxyethyl hydroperoxide; PAA: peroxyacetic acid; PPA: perpropionic acid.

(BHMP), methyl hydroperoxide (MHP), and ethyl hydroperoxide (EHP). Because the standard of BHMP is not available, BHMP is quantified using the response factor of HMHP. Figure 3 a shows the wall-loss-corrected molar yield profiles of $\mathrm{H}_{2} \mathrm{O}_{2}$, HMHP, and BHMP as a function of RH. The wall loss of MHP and EHP was considered to be the same as that of $\mathrm{H}_{2} \mathrm{O}_{2}$, while the wall loss of BHMP was assumed to be like HMHP. The molar yield was defined as the ratio of the formed molar number of the product to the consumed molar number of isoprene. Here, the percent conversion of isoprene was estimated to be $75 \%$, according to the rate constant of the isoprene reaction with $\mathrm{O}_{3}$ (Atkinson et al., 2006) and a reaction time of $68 \mathrm{~s}$. The molar yields of MHP and EHP were found to be $\sim 2 \%$ and $\sim 1 \%$, respectively, under every $\mathrm{RH}$ condition (not shown). HMHP and $\mathrm{H}_{2} \mathrm{O}_{2}$ increased with $\mathrm{RH}$ and then leveled off at $40 \% \mathrm{RH}$. An increasing humidity led to a decreasing molar yield of BHMP, indicating that the water effects on the formation of BHMP were different than the water effects on HMHP and $\mathrm{H}_{2} \mathrm{O}_{2}$. All the observed organic acids and carbonyls, including formic acid (FA), acetic acid (AA), formaldehyde (FAL), acetaldehyde (AL), methyl glyoxal (MG), and glyoxal (GL), were found to be dependent on RH (Fig. 3b); that is, there was a significant yield increase with increasing RH for AL, MG, and GL, while there was a slight yield decrease with increasing RH for FAL, FA, and AA.

\subsection{Unknown peroxides}

Interestingly, we detected three unknown peroxides, including unknown1 (retention time in HPLC: $12.88 \mathrm{~min}$ ), unknown2 (29.41 $\mathrm{min}$ ), and unknown3 (27.22 min). Because of the absence of standards for the three unknown peroxides, unknown1 was quantified using the response factor of peroxyacetic acid (PAA), as the retention time of unknown1
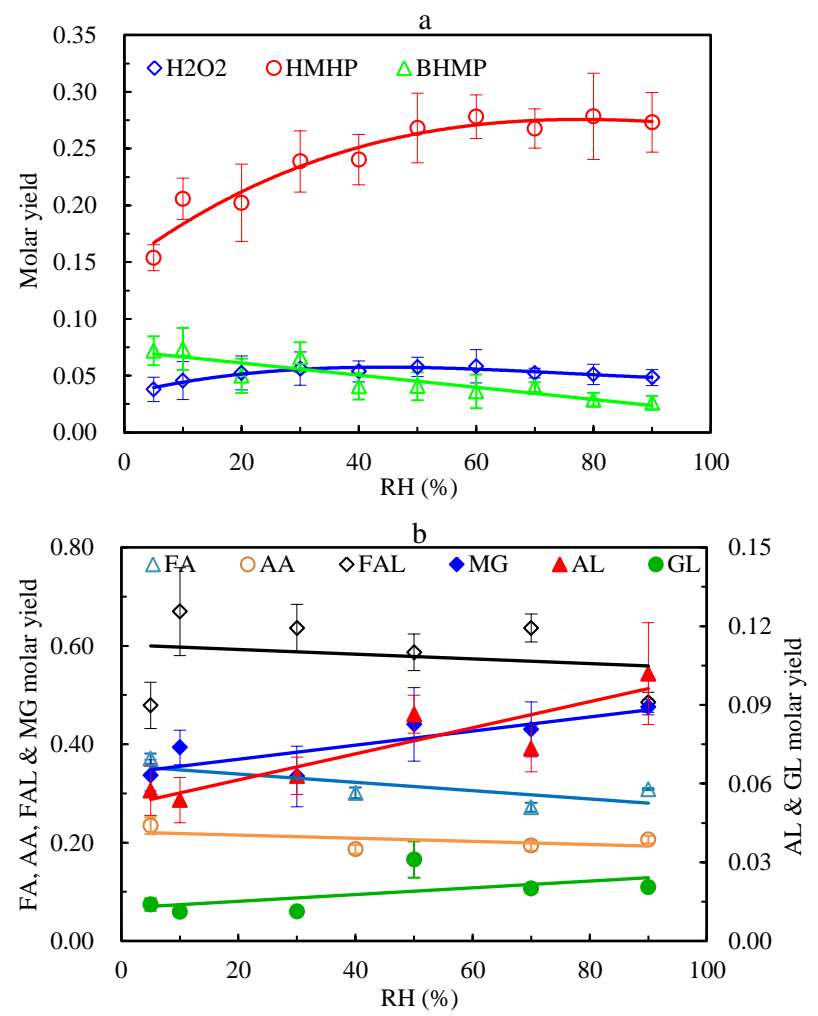

Fig. 3. Dependence of the product yields for (a) peroxides and (b) carbonyls and acids on relative humidity (RH). FA: formic acid; AA: acetic acid; FAL: formaldehyde; MG: methyl glyoxal; AL: acetaldehyde; GL: glyoxal.

was very close to that of PAA (13.22 min). Both unknown2 and unknown3 were quantified using the response factor of $\mathrm{H}_{2} \mathrm{O}_{2}$, since we have no standard very close to them. In our HPLC system, compared to $\mathrm{H}_{2} \mathrm{O}_{2}(6.25 \mathrm{~min})$, compounds with longer retention times have smaller response factors. If true, the amounts of unknown 2 and unknown 3 would be underestimated. As for the wall losses, we applied the wall loss curve of HMHP to the yields correction for these unknown peroxides and obtained upper limits of their yields. Simultaneously, the wall loss curve of $\mathrm{H}_{2} \mathrm{O}_{2}$ was used to obtain the lower limits of their yields. The largest difference between these two corrected curves was about $15 \%$. We averaged the wall loss ratio of $\mathrm{H}_{2} \mathrm{O}_{2}$ and $\mathrm{HMHP}$ and used the mean value to represent the wall losses of the unknown peroxides. Based on the semi-quantitative concentrations mentioned above, and considering the wall losses, we estimated the molar yields of these three unknown peroxides. Figure 4 shows the RH dependence for the molar yields for the unknown peroxides. Increasing the $\mathrm{RH}$ from $5 \% \mathrm{RH}$ to $90 \% \mathrm{RH}$ led to a $90 \%$ decrease in the molar yield for unknown $1,98 \%$ decrease for unknown2, and $83 \%$ decrease for unknown3. Obviously, the formation and removal mechanism of these peroxides is worth exploring. 


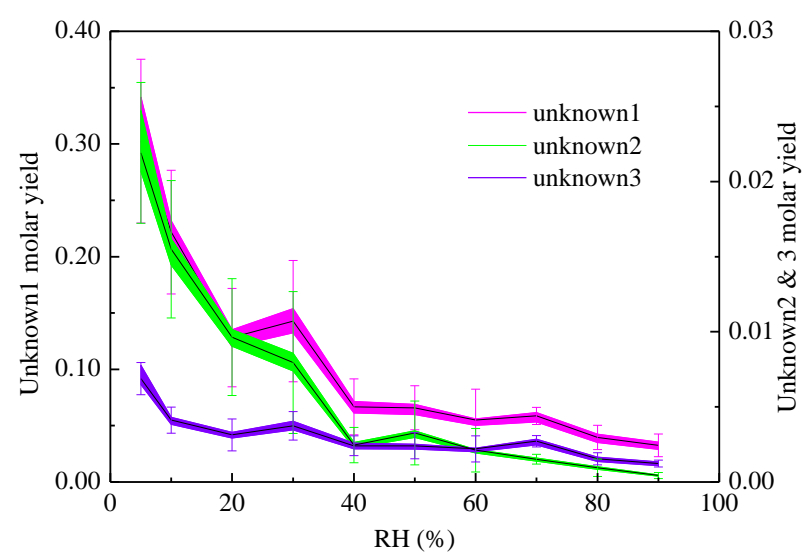

Fig. 4. Dependence of the product molar yields for the unknown peroxides on relative humidity $(\mathrm{RH})$. The upper edge of the filled area represents the corrected unknown peroxide yields using the wall loss curve of HMHP. The lower edge of the filled area represents the corrected unknown peroxide yields using the wall loss curve of $\mathrm{H}_{2} \mathrm{O}_{2}$. The black line represents the mean value, and the error bar represents $2 \sigma$ of the detected concentrations of unknown peroxides.

\subsubsection{Unknown peroxides source: ozonolysis reaction or $\mathrm{OH}$-initiated reaction?}

To explore the source of these peroxides, we needed to determine if they were from $\mathrm{O}_{3}$ or/and $\mathrm{OH}$ radical-initiated reactions. $\mathrm{OH}$ radicals are known to be generated in the gaseous ozonolysis of isoprene (e.g., Paulson and Orlando, 1996; Ariya et al., 2000; Kroll et al., 2001a, b). We performed an experiment of isoprene ozonolysis in the presence of the $\mathrm{OH}$ scavenger, cyclohexane, at $5 \% \mathrm{RH}$. The added cyclohexane was estimated to scavenge $95 \%$ of $\mathrm{OH}$ radicals produced from the reaction. A comparison of the initial reactant concentrations and the product yields in the presence and absence of the $\mathrm{OH}$ scavenger is shown in Table 1. The cyclohexane addition did not affect the molar yields of the unknown peroxides. This result suggested that the peroxides were produced via the ozonolysis reaction rather than an $\mathrm{OH}$ radical-initiated reaction.

\subsubsection{Unknown peroxides source: cross reaction of $\mathrm{RO}_{2}$ and $\mathrm{HO}_{2}$ radicals?}

It has been reported that Criegee radicals could produce $\mathrm{RO}_{2}$ as well as $\mathrm{HO}_{2}$ radicals, and the cross reaction of $\mathrm{RO}_{2}$ and $\mathrm{HO}_{2}$ would produce ROOH. In the MCM v3.2 mechanism for the ozonolysis of isoprene, the cross reaction of $\mathrm{RO}_{2}$ and $\mathrm{HO}_{2}$ resulted in the highest yield for $\mathrm{CH}_{3} \mathrm{OOH}$ (MHP), which was produced via the reaction of $\mathrm{CH}_{3} \mathrm{O}_{2}$ with $\mathrm{HO}_{2}$. However, a much lower yield was obtained for the more complicated ROOH compounds, about half to a tenth of the MHP yield. In the present laboratory study, we observed an MHP yield with only $\sim 2 \%$ at $5 \% \mathrm{RH}$, which is comparable to the 4-5\% reported in the literature (Gäb et al., 1995; Neeb et al., 1997). We observed a much higher yield for the more complicated organic peroxides, e.g., $\sim 30 \%$ for the unknown 1 peroxide as estimated using the response factor of peroxyacetic acid (PAA) in the HPLC analysis. The observed yield of MHP was much lower than that of the unknown peroxides; thus, the other $\mathrm{ROOH}$ compounds produced from the reactions of $\mathrm{RO}_{2}$ and $\mathrm{HO}_{2}$ presented a minor contribution to the formation of the observed organic peroxides.

\subsubsection{Unknown peroxides variation with reaction time}

Additional experiments that varied the flow were performed to investigate the reaction time dependence of the unknown peroxides. Flows of 3, 2, 1, and $0.5 \mathrm{~L} \mathrm{~min}^{-1}$ corresponded to reaction times of $45,68,135$, and $270 \mathrm{~s}$, respectively. In all these experiments, the initial concentrations of the reactants in the reactor were the same $(290 \mathrm{ppbv}$ isoprene $+80 \mathrm{ppmv}$ $\mathrm{O}_{3}$ ) and the $\mathrm{RH}$ is $5 \%$. We also determined the wall loss ratios $\left(\left(\mathrm{C}_{\mathrm{IN}}-\mathrm{C}_{\mathrm{OUT}}\right) / \mathrm{C}_{\mathrm{IN}}\right)$ of HMHP and $\mathrm{H}_{2} \mathrm{O}_{2}$ at different residence times and obtained an average wall loss variation that represented the wall loss residence time dependence of the three unknown peroxides: $8.3 \%$ at $45 \mathrm{~s}, 12.6 \%$ at $68 \mathrm{~s}$, $16.9 \%$ at $135 \mathrm{~s}$, and $15.2 \%$ at $270 \mathrm{~s}$, respectively. These wall losses were considered in the unknown peroxides concentration calculation. The results for the peroxides concentrations are shown in Fig. 5. Once the reaction began, the unknown peroxides increased to a maximum within $100 \mathrm{~s}$ and then gradually decreased. This indicated that the unknown peroxides were unstable; also they possibly reacted with the other compounds in the gas phase. Unfortunately, we could not exclude the case of heterogeneous decomposition of HAHPs during the reaction.

\subsubsection{Unknown peroxides decomposition in aqueous solution}

When we repeatedly measured a sample collected with the $\mathrm{H}_{3} \mathrm{PO}_{4}$ solution ( $\mathrm{pH} 3.5$ ) (the sample was stored in an Agilent brown sampling bottle at room temperature, $\sim 25^{\circ} \mathrm{C}$ ), we found that the concentrations of the unknown peroxides gradually decreased. Figure 6a shows the time series of the peroxides in the sample. Simultaneously, we monitored the carbonyl variation of the sample (shown in Fig. 6b). The concentration variation of methyl glyoxal (MG) mirrored that of the unknown peroxides, as it increased $30 \%$ after $130 \mathrm{~min}$ of storage at room temperature. Interestingly, we did not detect any compound that had more carbon than MG (C3 dicarbonyl). Moreover, the Henry's law constant of $\mathrm{O}_{3}\left(1.1 \times 10^{-2} \mathrm{M} \mathrm{atm}^{-1}\right.$, Seinfeld and Pandis, 2006) is so small that aqueous $\mathrm{O}_{3}$ would be negligible; thus, the aqueous ozonolysis reaction could not significantly contribute to MG production. Large radicals would be quickly stabilised by condensed water (Wang et al., 2012), and these radicals 
Table 1. The molar yields of the determined peroxides in the ozonolysis of isoprene in the presence and absence of the OH scavenger.

\begin{tabular}{|c|c|c|c|c|c|}
\hline Reactants & $Y_{\mathrm{H}_{2} \mathrm{O}_{2}}$ & $Y_{\text {HMHP }}$ & $Y_{\text {unkown1 }}$ & $Y_{\text {unknown2 }}$ & $Y_{\text {unknown3 }}$ \\
\hline 290 ppbv ISO +80 ppmv $_{3}$ & 0.051 & 0.185 & 0.263 & 0.018 & 0.005 \\
\hline 290 ppbv ISO +80 ppmv $\mathrm{O}_{3}+652$ ppmv $\mathrm{CH}$ & 0.043 & 0.207 & 0.249 & 0.018 & 0.004 \\
\hline 290 ppbv ISO +80 ppmv O $3+1956$ ppmv $\mathrm{CH}$ & 0.040 & 0.194 & 0.257 & 0.019 & 0.005 \\
\hline
\end{tabular}

Note: ISO, isoprene; $\mathrm{CH}$, cyclohexane.

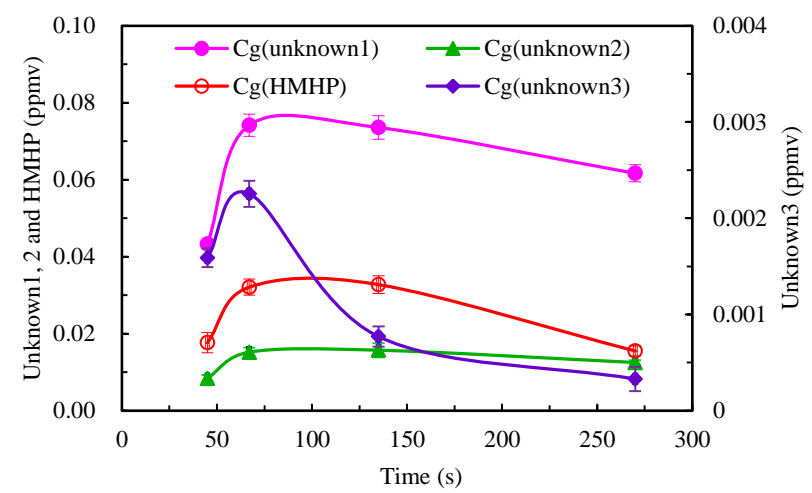

Fig. 5. The temporal profiles of HMHP and the three unknown peroxides at $5 \% \mathrm{RH}$.

could not constantly decompose and directly produce MG over such a long time. So, the source of MG remains obscure.

As shown in Fig. 6, the unknown peroxides decrease, whereas $\mathrm{H}_{2} \mathrm{O}_{2}$ and $\mathrm{MG}$ increase. In the $\mathrm{O}_{3}$-initiated reaction of isoprene, we expected that hydroxyalkyl hydroperoxides (HAHPs) would be produced from the reactions of the Criegee intermediates with $\mathrm{H}_{2} \mathrm{O}$ (Gäb et al., 1985; Hatakeyama and Akimoto, 1994; Ryzhkov and Ariya, 2004). However, in the past decade, researchers have identified few HAHPs larger than HMHP produced through the ozonolysis mechanism. The reason has been previously attributed to the faster decomposition into a carbonyl and $\mathrm{H}_{2} \mathrm{O}_{2}$ for larger HAHPs than HMHP (Hasson et al., 2001b). Notably, most of the previous studies employed a large static chamber, so possibly these studies missed details regarding the generation of peroxides at the beginning of the reaction as the first sample was usually collected after $10 \mathrm{~min}$ reaction. In the present study, we used a quartz flow tube reactor to investigate the formation of peroxides in the ozonolysis of isoprene at various RH. The reaction time was dozens of seconds and the wall losses of the peroxides were limited to a small extent; this increased the chance that we could observe some compounds that were active and short lived. The obvious opposite variations for the unknown peroxides and carbonyls and the analysis mentioned above led us to suppose that the observed unknown peroxides were the products of the Criegee intermediate reactions with $\mathrm{H}_{2} \mathrm{O}$ (i.e., HAHPs), and the in-
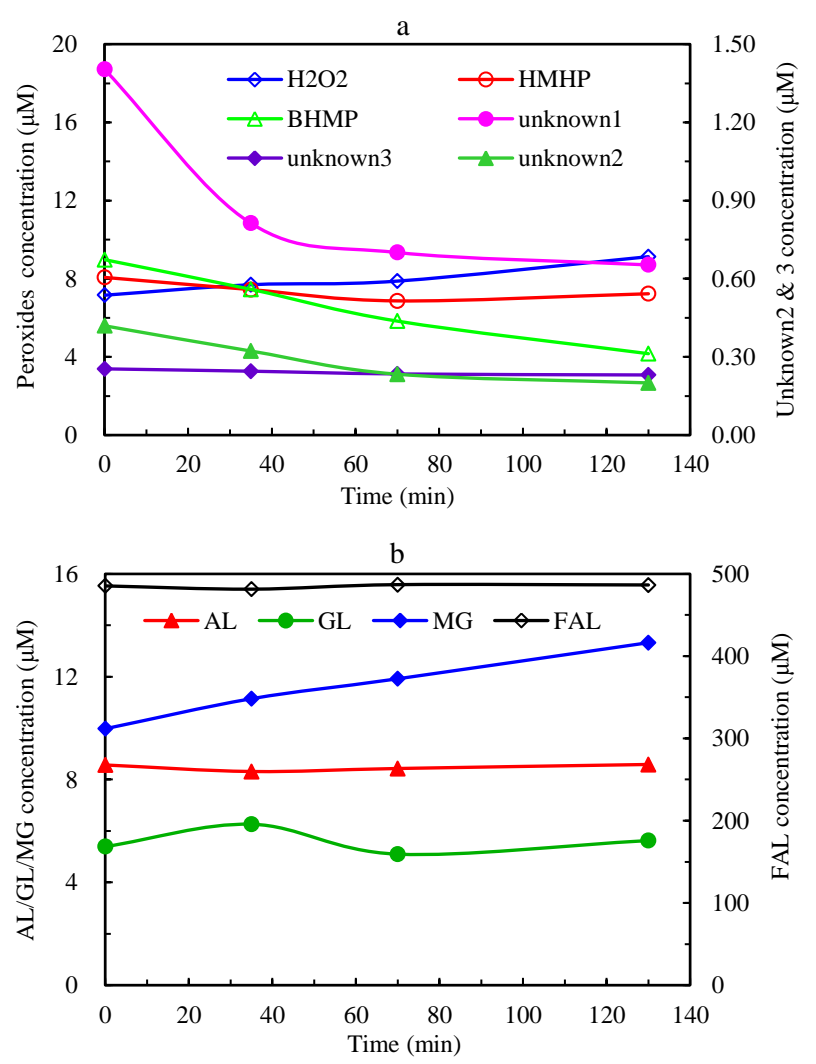

Fig. 6. Temporal profiles of (a) peroxides and (b) carbonyls of a sample collected with $\mathrm{H}_{3} \mathrm{PO}_{4}$ solution and stored at room temperature $\left(\sim 25^{\circ} \mathrm{C}\right)$. AL: acetaldehyde; GL: glyoxal; MG: methyl glyoxal; FAL: formaldehyde.

crease in the carbonyls such as MG was due to the aqueous decomposition of large HAHPs.

\subsubsection{Comparison with the synthesized peroxides}

Considering the inverse relationship between MG and the unknown peroxides described in Fig. 6, we attempted to evaluate whether MG was a potential precursor in the synthesis of the unknown peroxides. Unfortunately, MG polymerizes at a high concentration, and at a low concentration it did not react with $\mathrm{H}_{2} \mathrm{O}_{2}$ to generate the corresponding hydroxyl hydroperoxide. However, we tried to synthesize a series of organic peroxides including alkyl hydroperoxides, hydroxyalkyl hydroperoxides, and peroxy acids to confirm 
Table 2. Synthesized peroxides and their retention time, carbon number, and response factors. $\mathrm{H}_{2} \mathrm{O}_{2}$ and the three unknown peroxides are listed for comparison.

\begin{tabular}{|c|c|c|c|c|}
\hline Precursor & Peroxide & RT & $\mathrm{C}$ & $\mathrm{RF}$ \\
\hline $\mathrm{H}_{2} \mathrm{O}_{2}$ & $\mathrm{H}_{2} \mathrm{O}_{2}$ & 6.25 & 0 & 1 \\
\hline Glycoaldehyde & $\mathrm{CH}_{2}(\mathrm{OH}) \mathrm{CH}(\mathrm{OH}) \mathrm{OOH}$ & 6.72 & 2 & \\
\hline Formaldehyde & $\mathrm{CH}_{2}(\mathrm{OH}) \mathrm{OOH}$ [HMHP] & 7.14 & 1 & 1 \\
\hline Glyoxal & $\mathrm{HOOCH}(\mathrm{OH}) \mathrm{CH}(\mathrm{OH}) \mathrm{OOH}$ & 7.30 & 2 & \\
\hline Formic acid & $\mathrm{HC}(\mathrm{O}) \mathrm{OOH}$ & 8.61 & 1 & \\
\hline Glycolic acid & $\mathrm{CH}_{2}(\mathrm{OH}) \mathrm{C}(\mathrm{O}) \mathrm{OOH}$ & 8.72 & 2 & \\
\hline Formaldehyde & $\mathrm{HOCH}_{2} \mathrm{OOCH}_{2} \mathrm{OH}$ [BHMP] & 8.81 & 2 & \\
\hline 2-Br-ethanol & $\mathrm{CH}_{2}(\mathrm{OH}) \mathrm{CH}_{2} \mathrm{OOH}$ [2-HEHP] & 9.59 & 2 & \\
\hline Hydroxyacetone & $\mathrm{CH}_{2}(\mathrm{OH}) \mathrm{C}(\mathrm{OH})(\mathrm{OOH}) \mathrm{CH}_{3}$ & 9.61 & 3 & \\
\hline Dimethyl sulfate & $\mathrm{CH}_{3} \mathrm{OOH}[\mathrm{MHP}]$ & 9.75 & 1 & 0.07 \\
\hline Acetaldehyde & $\mathrm{CH}_{3} \mathrm{CH}(\mathrm{OH}) \mathrm{OOH}$ [1-HEHP] & 11.49 & 2 & \\
\hline - & Unknown1 & 12.88 & & \\
\hline Acetic acid & $\mathrm{CH}_{3} \mathrm{C}(\mathrm{O}) \mathrm{OOH}[\mathbf{P A A}]$ & 13.22 & 2 & 0.33 \\
\hline 3-Br-1-proanol & $\mathrm{HOCH}_{2} \mathrm{CH}_{2} \mathrm{CH}_{2} \mathrm{OOH}$ & 14.37 & 3 & \\
\hline 1-Br-2-proanol & $\mathrm{CH}_{3} \mathrm{CH}(\mathrm{OH}) \mathrm{CH}_{2} \mathrm{OOH}$ & 16.77 & 3 & \\
\hline Diethyl sulfate & $\mathrm{CH}_{3} \mathrm{CH}_{2} \mathrm{OOH}$ & 17.30 & 2 & 0.05 \\
\hline Acetone & $\mathrm{CH}_{3} \mathrm{C}(\mathrm{OH})(\mathrm{OOH}) \mathrm{CH}_{3}$ & 18.66 & 3 & \\
\hline Propanal & $\mathrm{CH}_{3} \mathrm{CH}_{2} \mathrm{CH}(\mathrm{OH}) \mathrm{OOH}$ & 26.28 & 3 & \\
\hline- & Unknown 3 & 27.22 & & \\
\hline- & Unknown 2 & 29.41 & & \\
\hline Propionic acid & $\mathrm{CH}_{3} \mathrm{CH}_{2} \mathrm{C}(\mathrm{O}) \mathrm{OOH}[\mathbf{P P A}]$ & 31.77 & 3 & \\
\hline
\end{tabular}

Note: RT, peroxide retention time (min) in HPLC analysis; C, carbon number; RF: response factor in HPLC analysis; [ ] represents the abbreviation of the peroxide.

the unknown peroxides. The detailed synthetic method can be found in the literature (Kok et al., 1995). The precursors and the peroxides as well as the HPLC retention times of the peroxides are shown in Table 2. Generally, MHP (EHP) was synthesized from $\mathrm{H}_{2} \mathrm{O}_{2}$ and dimethyl sulfate (diethyl sulfate) in the presence of $40 \% \mathrm{KOH}, \alpha$-hydroxyalkyl hydroperoxide was synthesized by the reaction of $\mathrm{H}_{2} \mathrm{O}_{2}$ and various carbonyls, other hydroxyalkyl hydroperoxides were synthesized from $\mathrm{H}_{2} \mathrm{O}_{2}$ and brominated alcohols in the presence of $\mathrm{KOH}$, and peroxy organic acids were synthesized by the reaction of $\mathrm{H}_{2} \mathrm{O}_{2}$ and organic acids. Unfortunately, none of these synthesized peroxides had the same retention time as one of the three unknown peroxides. Nevertheless, after comparing the retention time, carbon number, and functional groups of these synthesized peroxides, we obtained pattern about the retention time of the peroxides as follows. (1) For the hydroperoxides containing the same number of carbons: (i) the compound containing an $\mathrm{OH}$ group has a shorter retention time, e.g., $\mathrm{CH}_{2}(\mathrm{OH}) \mathrm{OOH}$ 7.14 min $<\mathrm{CH}_{3} \mathrm{OOH} 9.75 \mathrm{~min}$; (ii) hydroxyl hydroperoxide has a shorter retention time compared with peroxy acid, e.g., $\mathrm{CH}_{2}(\mathrm{OH}) \mathrm{OOH} 7.14 \mathrm{~min}<\mathrm{HC}(\mathrm{O}) \mathrm{OOH} 8.61 \mathrm{~min}$ and $\mathrm{CH}_{3} \mathrm{CH}(\mathrm{OH}) \mathrm{OOH} 11.49 \min <\mathrm{CH}_{3} \mathrm{C}(\mathrm{O}) \mathrm{OOH} 13.22 \mathrm{~min}$; and (iii) the further the hydroxyl group is from the peroxy group, the shorter is the retention time for the hydroxyl group containing peroxide, e.g., $\mathrm{CH}_{2}(\mathrm{OH}) \mathrm{CH}_{2} \mathrm{OOH}$ $9.59 \mathrm{~min}<\mathrm{CH}_{3} \mathrm{CH}(\mathrm{OH}) \mathrm{OOH} \quad 11.49 \mathrm{~min}$ and
$\mathrm{HOCH}_{2} \mathrm{CH}_{2} \mathrm{CH}_{2} \mathrm{OOH} 14.37 \min <\mathrm{CH}_{3} \mathrm{CH}(\mathrm{OH}) \mathrm{CH}_{2} \mathrm{OOH}$ $16.77 \mathrm{~min}$. (2) For the peroxides containing a different number of carbons: (i) one more carbon usually leads to a longer retention time, e.g., $\mathrm{CH}_{3} \mathrm{OOH} 9.75 \mathrm{~min}<\mathrm{CH}_{3} \mathrm{CH}_{2} \mathrm{OOH}$ $17.30 \mathrm{~min}$; and (ii) one more $\mathrm{C}(\mathrm{OH})$ group leads to a shorter retention time, e.g., $\mathrm{CH}_{2}(\mathrm{OH}) \mathrm{CH}(\mathrm{OH}) \mathrm{OOH}$ $6.72 \mathrm{~min}<\mathrm{CH}_{2}(\mathrm{OH}) \mathrm{OOH} 7.14 \mathrm{~min}$. Furthermore, we determined the stability of these synthesized peroxides. Alkyl hydroperoxides and peroxy organic acids are much more stable than hydroxyalkyl hydroperoxides. When stored in $\mathrm{H}_{3} \mathrm{PO}_{4}$ solution ( $\mathrm{pH}$ 3.5) at room temperature, alkyl hydroperoxides and peroxy acids decreased by less than $5 \%$ at a concentration of about $10^{-5} \mathrm{M}$ for $1 \mathrm{~h}$ of storage, while hydroxyalkyl hydroperoxides decreased by $5 \%$ to $40 \%$ (the larger the compound, the more stable it is). From Fig. 6a, we know that the unknown 1,2 , and 3 peroxides decreased $50 \%, 40 \%$, and $7 \%$, respectively. This was very similar to the variation in the hydroxyalkyl hydroperoxides in the $\mathrm{H}_{3} \mathrm{PO}_{4}$ solution.

According to these empirical laws for the retention time and the stability of the synthesized peroxides, we speculate that unknown1 is a hydroxyl- or a carbonyl-group-containing C2 hydroperoxide, or both hydroxyl- and carbonyl groupcontaining $\mathrm{C} 3$ hydroperoxide. Unknown2 and unknown3 are hydroxyl-group containing $\mathrm{C} 3$ hydroperoxides or peroxy organic acids or hydroxyl- and/or carbonylgroup-containing $\mathrm{C} 4$ hydroperoxides. Thus, we suggest that the MG HAHP 
$\left(\mathrm{CH}_{3} \mathrm{C}(\mathrm{OH})(\mathrm{OOH}) \mathrm{CHO}\right.$ or $\left.\mathrm{CH}_{3} \mathrm{C}(=\mathrm{O}) \mathrm{CH}(\mathrm{OH}) \mathrm{OOH}\right)$ is at least one of the three unknown peroxides.

\subsubsection{Possibility of peroxyhemiacetals}

It has been suggested that Criegee intermediates can react with carboxylic acids to form $\alpha$-acyloxyl hydropreroxides, and the $\alpha$-acyloxyl hydroperoxides can subsequently react with aldehydes to form peroxyhemiacetals via heterogeneous and aqueous phase reactions (Tobias and Ziemann, 2001; Zhao et al., 2012). In the present study, formic acid (FA), acetic acid (AA), formaldehyde (FAL), and acetaldehyde (AL) were detected in the ozonolysis of isoprene performed in the flow reactor, indicating the possibility of the formation of $\alpha$-acyloxyl hydroperoxides and peroxyhemiacetals on the reactor wall or in the collection solution. Thus, we added pairs of carboxylic acids and aldehydes with a much higher concentration (a few hundred ppbv), including $(\mathrm{FA}+\mathrm{FAL}),(\mathrm{FA}+\mathrm{AL}),(\mathrm{AA}+\mathrm{FAL})$, and $(\mathrm{AA}+\mathrm{AL})$, into the isoprene ozonolysis system. The results of these additional experiments show the formation of new peroxide species, which are possibly peroxyhemiacetals. On the basis of the retention time in HPLC, however, these species cannot be attributed to those three unknown peroxides.

In summary, consistent with their instability in solution, the variation of their yield with RH, and their HPLC retention time, we tentatively assigned the three unknown peroxides to be HAHPs, produced by the reaction of large Criegee intermediates with water molecules.

\subsection{Mechanism and water effect modelling}

To further test our hypothesis of HAHPs formation, we used a box model coupled with a near-explicit mechanism for the ozonolysis of isoprene (extracted from the MCM v3.2 mechanism) to simulate the reaction processes of the $\mathrm{O}_{3}$-initiated oxidation of isoprene. The extracted mechanism provides the reactions of seven Criegee intermediates as they react with water, directly producing carbonyls plus $\mathrm{H}_{2} \mathrm{O}_{2}$ or organic acids plus $\mathrm{H}_{2} \mathrm{O}$. The seven Criegee intermediates are $\mathrm{CH}_{2} \mathrm{OO}$, MVKOO $\left[\mathrm{CH}_{3} \mathrm{C}(\mathrm{OO}) \mathrm{CH}=\mathrm{CH}_{2}\right]$, MACROO $\left[\mathrm{CH}_{3} \mathrm{C}\left(=\mathrm{CH}_{2}\right) \mathrm{CHOO}\right], \quad \mathrm{MGLOO} \quad\left[\mathrm{CH}_{3} \mathrm{C}(=\mathrm{O}) \mathrm{CHOO}\right]$, MGLYOO $\left[\mathrm{CH}_{3} \mathrm{C}(\mathrm{OO}) \mathrm{CHO}\right], \mathrm{CH}_{3} \mathrm{CHOO}$, and HMGLOO $\left[\mathrm{CH}_{2}(\mathrm{OH}) \mathrm{C}(=\mathrm{O}) \mathrm{CHOO}\right]$. However, a number of experimental studies have affirmed the formation of HMHP (the simplest HAHP), produced via a reaction of $\mathrm{CH}_{2} \mathrm{OO}$ with $\mathrm{H}_{2} \mathrm{O}$ and yielding less than $1 \%$ to $30 \%$ under different humidities in the gas phase ozonolysis of isoprene (Gäb et al., 1995; Neeb et al., 1997; Sauer et al., 1999). Several theoretical studies suggest that the formation of HAHPs is the main reaction path for the reactions of the Criegee intermediates with water molecules (Aplincourt and Anglada, 2003a; Hasson et al., 2003) or the water dimer (Ryzhkov and Ariya, 2004). Subsequently, the unimolecular decomposition for HAHPs is unlikely to occur in the gas phase (Aplincourt and Anglada, 2003b; Hasson et al., 2003); only the waterassisted decomposition of HAHPs is efficient in the gas phase (Scheme 1, R (4a13) and R (4a14)), and it generates carbonyls plus $\mathrm{H}_{2} \mathrm{O}_{2}$ or organic acids plus $\mathrm{H}_{2} \mathrm{O}$ (Aplincourt and Anglada, 2003b). Therefore, we added the formation and decomposition of HAHPs into the extracted MCM mechanism. We suggest that the seven Criegee intermediates react with water and produce the corresponding HAHPs as follows:

$\mathrm{CH}_{2} \mathrm{OO}+\mathrm{H}_{2} \mathrm{O} \rightarrow \mathrm{CH}_{2}(\mathrm{OH}) \mathrm{OOH}[\mathbf{P O 1}] \stackrel{\mathrm{H}_{2} \mathrm{O}}{\longrightarrow}$ products

$\mathrm{CH}_{3} \mathrm{C}(\mathrm{OO}) \mathrm{CH}=\mathrm{CH}_{2}+\mathrm{H}_{2} \mathrm{O} \rightarrow$

$\mathrm{CH}_{3} \mathrm{C}(\mathrm{OH})(\mathrm{OOH}) \mathrm{CH}=\mathrm{CH}_{2}$ [PO2] $\stackrel{\mathrm{H}_{2} \mathrm{O}}{\longrightarrow}$ products

$\mathrm{CH}_{3} \mathrm{C}\left(=\mathrm{CH}_{2}\right) \mathrm{CHOO}+\mathrm{H}_{2} \mathrm{O} \rightarrow$

$\mathrm{CH}_{3} \mathrm{C}\left(=\mathrm{CH}_{2}\right) \mathrm{CH}(\mathrm{OH}) \mathrm{OOH}$ [PO3] $\stackrel{\mathrm{H}_{2} \mathrm{O}}{\longrightarrow}$ products

$\mathrm{CH}_{3} \mathrm{C}(=\mathrm{O}) \mathrm{CHOO}+\mathrm{H}_{2} \mathrm{O} \rightarrow \mathrm{CH}_{3} \mathrm{C}(=\mathrm{O}) \mathrm{CH}(\mathrm{OH}) \mathrm{OOH}$ [PO4] $\stackrel{\mathrm{H}_{2} \mathrm{O}}{\longrightarrow}$ products

$\mathrm{CH}_{3} \mathrm{C}(\mathrm{OO}) \mathrm{CHO}+\mathrm{H}_{2} \mathrm{O} \rightarrow \mathrm{CH}_{3} \mathrm{C}(\mathrm{OH})(\mathrm{OOH}) \mathrm{CHO}$ [PO5] $\stackrel{\mathrm{H}_{2} \mathrm{O}}{\longrightarrow}$ products

$\mathrm{CH}_{3} \mathrm{CHOO}+\mathrm{H}_{2} \mathrm{O} \rightarrow \mathrm{CH}_{3} \mathrm{CH}(\mathrm{OH}) \mathrm{OOH}\left[\right.$ PO6] $\stackrel{\mathrm{H}_{2} \mathrm{O}}{\longrightarrow}$ products

$\mathrm{CH}_{2}(\mathrm{OH}) \mathrm{C}(=\mathrm{O}) \mathrm{CHOO}+\mathrm{H}_{2} \mathrm{O} \rightarrow$ $\mathrm{CH}_{2}(\mathrm{OH}) \mathrm{C}(=\mathrm{O}) \mathrm{CH}(\mathrm{OH}) \mathrm{OOH}$ [PO7] $\stackrel{\mathrm{H}_{2} \mathrm{O}}{\longrightarrow}$ products

The formation rate constants for these HAHPs from the combination of Criegee radicals with water were estimated on the basis of a theoretical study by Ryzhkov and Ariya (2004), who provided the reaction rate constants of parent, mono-, and dimethyl-substituted Criegee intermediates with water. For the water-assisted decomposition of HAHPs, only the rate constant for 2-propenyl $\alpha$-hydroxy hydroperoxide (PO3) is available (Aplincourt and Anglada, 2003b), that is, $1.5 \times 10^{-30} \mathrm{~cm}^{3}$ molecule $\mathrm{s}^{-1}$. However, our model results indicate that this theoretical decomposition rate constant is too small to be consistent with experimental observations of the profile of PO3 variation with RH. Thus, we treated the exponent of the rate constant as an adjustable parameter. A sensitivity analysis was performed and 14 simulations were performed for $\mathrm{PO} 3$ using $-30,-28,-25,-22$, $-21,-20$, and -19 as the exponents of the rate constant at two RHs (70\% and $10 \%$, Fig. 7). As a result, $-21,-20$, and -19 could capture the variation of the concentration of HAHPs with RH. PO3 decreased by $53 \%$ as RH increased from $10 \%$ to $70 \%$ at $68 \mathrm{~s}$, which is similar to the $80 \%$ decrease for unknown2 (Fig. 4). Furthermore, for exponent $=-20$, the simulated time series of PO3 would preferably match the observed unknown2 (Fig. 7). 


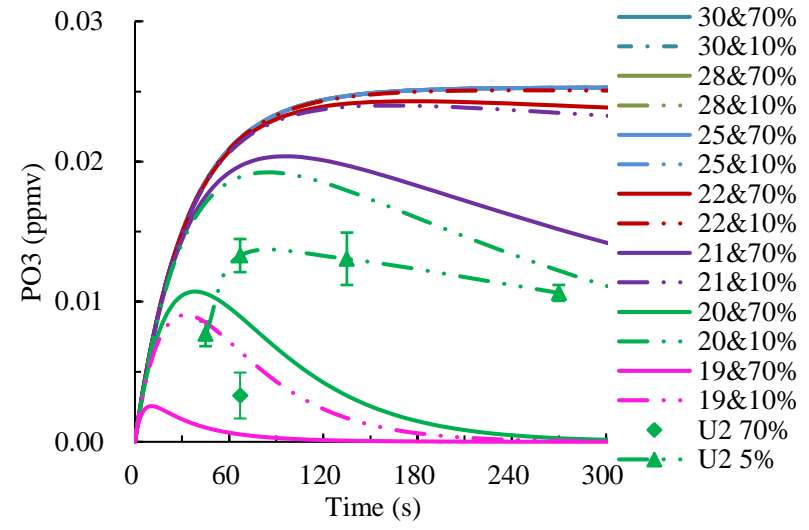

Fig. 7. Sensitivity simulation for the exponent of the reaction rate constant of PO3 and water. The number before " $\&$ " is the negative exponent, and the number after " $\&$ " is the relative humidity $(\mathrm{RH})$. For example, $30 \& 70 \%$ means the model is performed with a rate constant of $1.5 \times 10^{-30} \mathrm{~cm}^{3}$ molecule $\mathrm{s}^{-1} \mathrm{~s}^{-1}$ and a RH of $70 \%$. U2 $70 \%$ and $\mathrm{U} 25 \%$ represent the observed unknown 2 time series at $70 \% \mathrm{RH}$ and $5 \% \mathrm{RH}$, respectively.

We hypothesized that all seven HAHPs (PO1-PO7) have the similar rate constant of $1.5 \times 10^{-20} \mathrm{~cm}^{3}$ molecule $\mathrm{s}^{-1}$. We then used the modified mechanism to simulate the concentration variations of the seven HAHPs with RH at $68 \mathrm{~s}$ (Fig. 8). The simulation results displayed that $\mathrm{PO} 1, \mathrm{PO}$, PO3, PO4, PO5, PO6, and PO7 decreased by $91 \%, 80 \%$, $95 \%, 76 \%, 53 \%, 84 \%, 81 \%$, and $87 \%$, respectively, with RH increasing from $10 \%$ to $90 \%$. These decreases showed good agreement with the observed decreases for the unknown peroxides, that is, $90 \%$ for unknown $1,98 \%$ for unknown 2 , and $83 \%$ for unknown3 with RH increasing from $10 \%$ to $90 \%$ (see Sect. 3.3). Interestingly, for the concentration curves, $\mathrm{PO} 2$ and $\mathrm{PO} 3$ agreed well with unknown2 (Fig. 8a), and PO4, PO5, and PO6 agreed well with unknown3 (Fig. 8b). Meanwhile, all of the POs were much lower than unknown1, although their variation trends were similar. This discrepancy between the POs and unknown1 seems to indicate an overestimation of the decomposition rate constant for some PO, or an overestimation of the unknown 1 concentration due to the absence of its standard calibration in HPLC analysis.

The expected dependence of PO1 (i.e., HMHP) on RH was significantly different from that observed in the experiment. The modelled HMHP decreased with increasing RH, while the observed HMHP increased gradually with increasing RH and then leveled off. This may have been due to the chemistry of BHMP. Gäb et al. (1985) reported that HMHP would react with $\mathrm{HCHO}$ to generate BHMP in the gas phase, and BHMP would produce HMHP by hydrolysis. Our experimental results indicated that BHMP formed during the ozonolysis of isoprene. The RH dependence profiles of measured molar yields of HMHP, BHMP and the modelled PO1
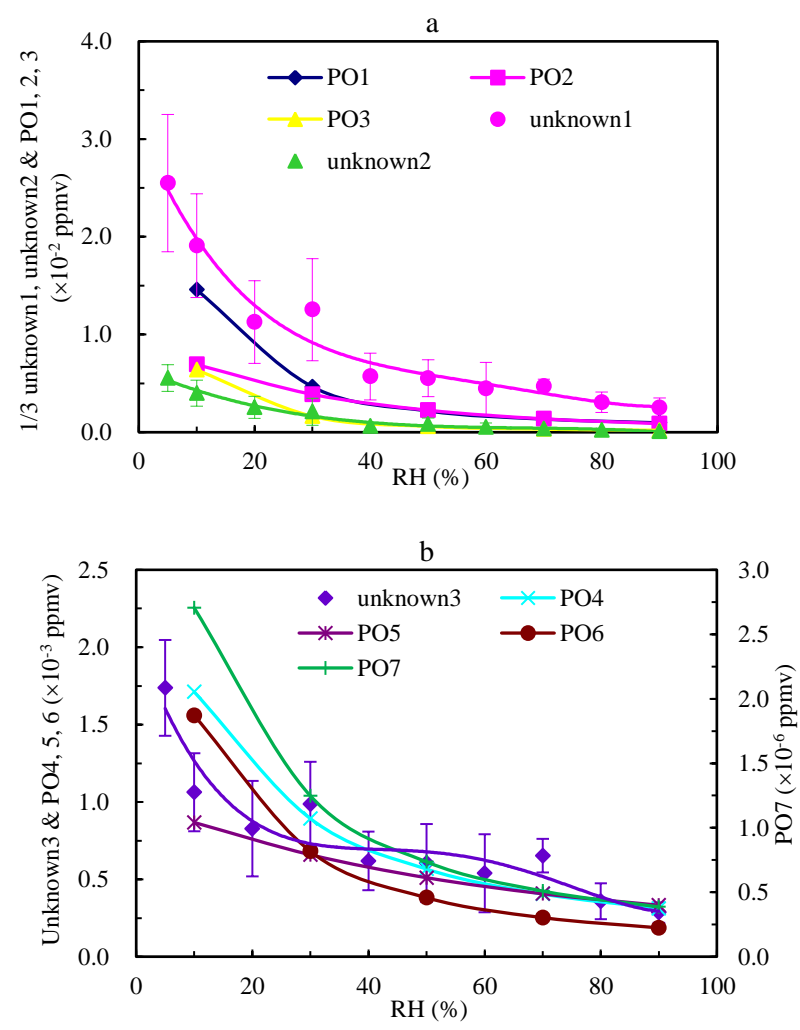

Fig. 8. The simulated dependence of the concentrations of seven POs on the relative humidity $(\mathrm{RH})$, and comparisons between the modelled PO and the observed unknown peroxides. (a) Observed unknown1, unknown2, and modelled PO1, 2, and 3. (b) Observed unknown3 and modelled PO4, 5, 6, and 7.

together with the corresponding linear fitting equations are showed in Fig. 9. It is noticed that the modelled HMHP, i.e., PO1, is far less than the measured HMHP. Moreover, as $\mathrm{RH}$ increases, the decrement of BHMP due to its hydrolysis $\left(Y_{\mathrm{BHMP}} / \mathrm{RH}=5.36 \times 10^{-4}\right)$ can only account for about half the increment of HMHP $\left(Y_{\mathrm{HMHP}} / \mathrm{RH}=1.26 \times 10^{-3}\right)$. There are two possible reasons to explain this result as follows: (i) there is other source of HMHP, and (ii) it is more difficult for HMHP to hydrolyze at high RH than that for the HAHPs containing more carbons. Unfortunately, we currently cannot give a definite interpretation about the discrepancy between the modelled and observed HMHP.

In summary, the simulation results were consistent with the speculation that the detected unknown peroxides are HAHPs produced from the reaction of Criegee intermediates and water molecules. 


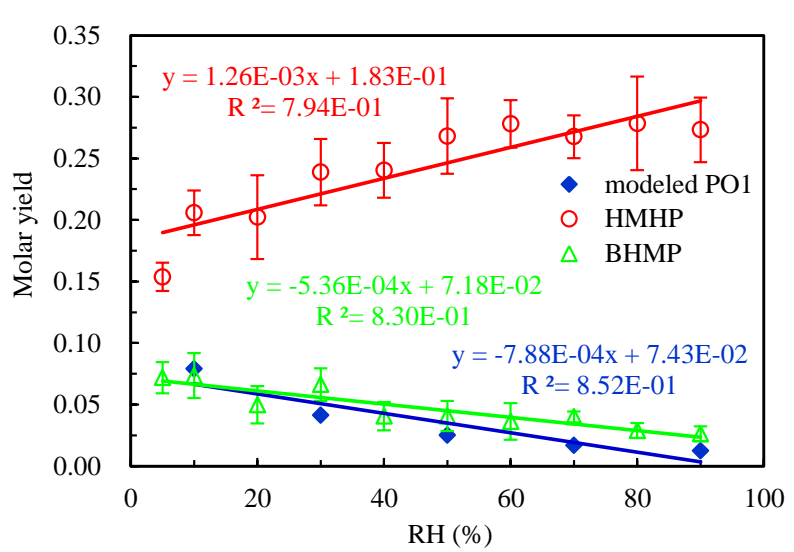

Fig. 9. Comparison of RH dependence profiles of measured HMHP, BHMP and modelled PO1 (i.e., HMHP).

\section{Conclusions and atmospheric implications}

We investigated the formation of peroxides in the gas phase ozonolysis of isoprene at various relative humidities on a reaction time scale of tens of seconds using a quartz flow tube coupled with an online HPLC detection. This relatively quick detection method enabled the detection of both conventional and unknown organic peroxides formed during the reaction. The conventional peroxides, including $\mathrm{H}_{2} \mathrm{O}_{2}$, HMHP, BHMP, and MHP, were identified and quantified, and they showed good agreement with previous studies. Interestingly, three unknown peroxides were detected and were characterised as follows: (1) their molar yields decreased significantly with increasing relative humidity (RH); (2) their concentrations varied with the reaction time, indicating their instability; (3) they decomposed into carbonyls plus $\mathrm{H}_{2} \mathrm{O}_{2}$ in an aqueous solution; and (4) they were $\mathrm{C} 2-\mathrm{C} 4$ species and contained a hydroxyl and/or carbonyl group, but could not be attributed to peroxyhemiacetal species. These characteristics are consistent with those of hydroxyalkyl hydroperoxides (HAHPs). As illustrated in Scheme 1, the Criegee intermediates produced from the reaction of ozone with isoprene reacted with water and generated a series of HAHPs. Thus, HAHPs are the likeliest candidates for the unknown peroxides. We used a box model coupled with a modified nearexplicit mechanism extracted from MCM v3.2 to try to produce the HAHPs profiles with RH variation. The modelled HAHP profiles showed good agreement with those of the three unknown peroxides observed in the experiments. This provided evidence in support of our suggestion that these unknown peroxides are the products of the Criegee intermediates reaction with water. Obviously, synthesizing the standards of HAHPs is urgently needed.

The present study may experimentally prove that, instead of a one-step reaction, Criegee intermediates react with water and then generate carbonyls plus $\mathrm{H}_{2} \mathrm{O}_{2}$, or organic acids plus $\mathrm{H}_{2} \mathrm{O}$, via the formation of hydroxyalkyl hydroperox- ides. On the basis of the experimental results of the formation kinetics and the RH-dependent molar yield of HAHPs, and the model-fitted $\mathrm{HAHP}+\mathrm{H}_{2} \mathrm{O}$ reaction rate constant of $1.5 \times 10^{-20} \mathrm{~cm}^{3}$ molecule ${ }^{-1} \mathrm{~s}^{-1}$, we estimate that the lifetime of HAHPs due to their reaction with water is 10 to $90 \mathrm{~min}$ at $25^{\circ} \mathrm{C}$ and $10-90 \% \mathrm{RH}$. This lifetime favours the reaction of HAHPs with other species (such as carbonyls and acids) to produce peroxyhemiacetals, and thus contributes to the formation of SOAs. Moreover, HAHPs will have enough time to distribute between the gaseous and aqueous phases. Because they are soluble, they will participate in the chemistry of atmospheric aqueous phases, including cloud, fog, and wet aerosols.

Acknowledgements. The authors gratefully thank the National Natural Science Foundation of China (grants 21077003 and 41275125) and the State Key Laboratory of Environment Simulation and Pollution Control (special fund 10Z03ESPCP) for their financial support, and the help from J. L. Li, College of Environmental Sciences and Engineering of Peking University, for model discussions.

Edited by: P. O. Wennberg

\section{References}

Aplincourt, P. and Anglada, J. M.: Theoretical studies of the isoprene ozonolysis under tropospheric conditions. 1. Reaction of substituted carbonyl oxides with water, J. Phys. Chem. A., 107, 5798-5811, 2003a.

Aplincourt, P. and Anglada, J. M.: Theoretical studies of the isoprene ozonolysis under tropospheric conditions. 2. Unimolecular and water-assisted decomposition of the $\alpha$-hydroxy hydroperoxides, J. Phys. Chem. A., 107, 5812-5820, 2003 b.

Ariya, P. A., Sander, R., and Crutzen, P. J.: Significance of $\mathrm{HO}_{\mathrm{x}}$ and peroxides production due to alkene ozonolysis during the fall and winter: A modeling study, J. Geophys. Res., 105, 17721-17738, 2000.

Atkinson, R. and Arey, J.: Atmospheric degradation of volatile organic compounds, Chem. Rev., 103, 4605-4683, 2003.

Atkinson, R., Aschmann, S. M., Arey, J., and Shorees, B.: Formation of $\mathrm{OH}$ radicals in the gas-phase reactions of $\mathrm{O}_{3}$ with a series of terpenes, J. Geophys. Res., 97D, 6065-6073, 1992.

Atkinson, R., Baulch, D. L., Cox, R. A., Crowley, J. N., Hampson, R. F., Hynes, R. G., Jenkin, M. E., Rossi, M. J., Troe, J., and IUPAC Subcommittee: Evaluated kinetic and photochemical data for atmospheric chemistry: Volume II - gas phase reactions of organic species, Atmos. Chem. Phys., 6, 3625-4055, doi:10.5194/acp-6-3625-2006, 2006.

Becker, K. H., Brockmann, K. J., and Bechara, J.: Production of hydrogen peroxide in forest air by reaction of ozone with terpenes, Nature, 346, 256-258, 1990.

Bonn, B., von Kuhlmann, R., and Lawrence, M. G.: High contribution of biogenic hydroperoxides to secondary organic aerosol formation, Geophys. Res. Lett., 31, L10108, doi:10.1029/2003GL019172, 2004. 
Calvert, J. G., Lazrus, A. L., Kok, G. L., Heikes, B. G., Welega, J. G., Lind, J. and Cantrell, C. A.: Chemical mechanism of acid generation in the troposphere, Nature, 317, 27-35, 1985.

Chen, Q., Liu, Y. J., Donahue, N. M., Shilling, J. E., and Martin, S. T.: Particle-phase chemistry of secondary organic material: Modeled compared to measured O:C and $\mathrm{H}: \mathrm{C}$ elemental ratios provide constraints, Environ. Sci. Technol., 45, 4763-4770, 2011.

Crehuet, R., Anglada, J. M., and Bofill, J. M.: Tropospheric formation of hydroxymethyl hydroperoxide, formic acid, $\mathrm{H}_{2} \mathrm{O}_{2}$, and $\mathrm{OH}$ from carbonyl oxide in the presence of water vapour: a theoretical study of the reaction mechanism, Chem. Eur. J., 7, 22272235, 2001.

Docherty, K. S., Wu, W., Lim, Y. B., and Ziemann, P. J.: Contributions of organic peroxides to secondary aerosol formed from reactions of monoterpenes with $\mathrm{O}_{3}$, Environ. Sci. Technol., 39, 4049-4059, 2005.

Gäb, S., Hellpointner, E., Turner, W. V., and Korte, F.: Hydroxymethyl hydroperoxide and bis(hydroxymethyl) peroxide from gas phase ozonolysis of naturally occurring alkenes, Nature, 316, 535-536, 1985.

Gäb, S., Turner, W. V., and Wolff, S.: Formation of alkyl and hydroxyalkyl hydroperoxides on ozonolysis in water and in air, Atmos. Environ., 29, 2401-2407, 1995.

Hallquist, M., Wenger, J. C., Baltensperger, U., Rudich, Y., Simpson, D., Claeys, M., Dommen, J., Donahue, N. M., George, C., Goldstein, A. H., Hamilton, J. F., Herrmann, H., Hoffmann, T., Iinuma, Y., Jang, M., Jenkin, M. E., Jimenez, J. L., Kiendler-Scharr, A., Maenhaut, W., McFiggans, G., Mentel, Th. F., Monod, A., Prévôt, A. S. H., Seinfeld, J. H., Surratt, J. D., Szmigielski, R., and Wildt, J.: The formation, properties and impact of secondary organic aerosol: current and emerging issues, Atmos. Chem. Phys., 9, 5155-5236, doi:10.5194/acp-9-51552009, 2009.

Hasson, A. S., Orzechowska, G., and Paulson, S. E.: Production of stabilized Criegee intermediates and peroxides in the gas phase ozonolysis of alkenes 1 . Ethene, trans-2-butene, and 2,3dimethyl-2-butene, J. Geophys. Res., 106, 34131-34142, 2001 a.

Hasson, A. S., Ho, A. W., Kuwata, K. T., and Paulson, S. E.: Production of stabilized Criegee intermediates and peroxides in the gas phase ozonolysis of alkenes 2 . Asymmetric and biogenic alkenes, J. Geophys. Res., 106, 34143-34153, 2001b.

Hasson, A. S., Chung, M. Y., Kuwata, K. T., Converse, A. D., Krohn, D., and Paulson, S. E.: Reaction of Criegee intermediates with water vapour- an additional source of $\mathrm{OH}$ radicals in alkene ozonolysis?, J. Phys. Chem. A., 107, 6176-6182, 2003.

Hatakeyama, S. and Akimoto, H.: Reactions of Criegee intermediates in the gas phase, Res. Chem. Intermed., 20, 503-524, 1994.

Hatakeyama, S., Izumi, K., Fukuyama, T., Akimoto, H., and Washida, N.: Reactions of $\mathrm{OH}$ with a-pinene and b-pinene in air: estimate of global $\mathrm{CO}$ production from the atmosheric oxidation of terpenes, J. Geophys. Res., 96, 947-958, 1991.

Hewitt, C. N. and Kok, G. L.: Formation and occurrence of organic hydroperoxides in the troposphere: Laboratory and field observations, J. Atmos. Chem., 12, 181-194, 1991.

Hewitt, C. N., Kok, G. L., and Fall, R.: Hydroperoxides detected in plants exposed to ozone mediate air pollution damage to alkene emitters, Nature, 344, 56-58, 1990.

Horie, O., Neeb, P., Limbach, S., and Moortgat, G. K.: Formation of formic acid and organic peroxides in the ozonolysis of ethene with added water vapour, Geophys. Res. Lett., 21, 1523-1526, 1994.

Hua, W., Chen, Z. M., Jie, C. Y., Kondo, Y., Hofzumahaus, A., Takegawa, N., Chang, C. C., Lu, K. D., Miyazaki, Y., Kita, K., Wang, H. L., Zhang, Y. H., and Hu, M.: Atmospheric hydrogen peroxide and organic hydroperoxides during PRIDE-PRD'06, China: their concentration, formation mechanism and contribution to secondary aerosols, Atmos. Chem. Phys., 8, 6755-6773, doi:10.5194/acp-8-6755-2008, 2008.

Huang, D., Zhang, X., Chen, Z. M., Zhao, Y., and Shen, X. L.: The kinetics and mechanism of an aqueous phase isoprene reaction with hydroxyl radical, Atmos. Chem. Phys., 11, 7399-7415, doi:10.5194/acp-11-7399-2011, 2011.

Jenkin, M. E., Saunders, S. M., and Pilling, M. J.: The tropospheric degradation of volatile organic compounds: a protocol for mechanism development, Atmos. Environ., 31, 81-104, 1997.

Kok, G. L., Mclaren, S. E., and Staffelbach, T. A.: HPLC determination of atmospheric organic hydroperoxides, J. Atoms. Oceanic. Technol., 12, 282-289, 1995.

Kroll, J. H., Clarke, J. S., Donahue, N. M., Anderson, J. G., and Demerjian, K. L.: Mechanism of $\mathrm{HO}_{\mathrm{x}}$ formation in the gas-phase ozone-alkene reaction. 1. Direct pressure-dependent measurements of prompt $\mathrm{OH}$ yields, J. Phys. Chem. A., 105, 1554-1560, 2001a.

Kroll, J. H., Sahay, S. R., Anderson, J. G., Demerjian, K. L., and Donahue, N. M.: Mechanism of $\mathrm{HO}_{\mathrm{x}}$ formation in the gas-phase ozone-alkene reaction. 2. Prompt versus thermal dissociation of carbonyl oxides to form OH, J. Phys. Chem. A., 105, 4446-4457, $2001 b$.

Kroll, J. H., Ng, N. L., Murphy, S. M., Flagan, R., and Seinfeld, J. H.: Secondary organic aerosol formation from isoprene photooxidation, Environ. Sci. Technol., 40, 1869-1877, 2006.

Lee, M., Heikes, B. G., and O'Sullivan, D. W.: Hydrogen peroxide and organic hydroperoxide in the troposphere: a review, Atmos. Environ., 34, 3475-3794, 2000.

Lightfoot, P. D., Roussel, P., Caralp, F., and Lesclaux, R.: Flash photolysis study of the $\mathrm{CH}_{3} \mathrm{O}_{2}+\mathrm{CH}_{3} \mathrm{O}_{2}$ and $\mathrm{CH}_{3} \mathrm{O}_{2}+$ $\mathrm{HO}_{2}$ reactions between 600 and $719 \mathrm{~K}$ : Unimolecular decomposition of methylhydroperoxide, J. Chem. Soc., Faraday Trans., 87, 3213-3220, 1991.

Miyoshi, A., Hatakeyama, S., and Washida, N.: OH radical-initiated photooxidation of isoprene: An estimate of global CO production, J. Geophys. Res., 99, 18779-18787, 1994.

Neeb, P., Sauer, F., Horie, O., and Moortgat, G. K.: Formation of hydroxymethyl hydroperoxide and formic acid in alkene ozonolysis in the presence of water vapour, Atmos. Environ., 31, 14171423, 1997.

Paulot, F., Crounse, J. D., Kjaergaard, H. G., Kurten, A., St Clair, J. M., Seinfeld, J. H., and Wennberg, P. O.: Unexpected epoxide formation in the gas-phase photooxidation of isoprene, Science, 325, 730-733, 2009.

Paulson, S. E. and Orlando, J. J.: The reactions of ozone with alkenes: An important source of $\mathrm{HO}_{\mathrm{x}}$ in the boundary layer, Geophys. Res. Lett., 23, 3727-3730, doi:10.1029/96GL03477, 1996.

Pellinen, R., Korhonen, M. S., Tauriainen, A. A., Palva, E. T., and Kangasjärvi, J.: Hydrogen peroxide actives cell death and defense gene expression in birch, Plant Physiol., 130, 549-560, 2002. 
Ravetta, F., Jacob, D. J., Brune, W. H., Heikes, B. G., Anderson, B. E., Blake, D. R., Gregory, G. L., Sachse, G. W., Sandholm, S. T., Shetter, R. E., Singh, H. B., and Talbot, R. W.: Experimental evidence for the importance of convected methylhydroperoxide as a source of hydrogen oxide $\left(\mathrm{HO}_{\mathrm{x}}\right)$ radicals in the tropical upper troposphere, J. Geophys. Res., 106, 32709-32716, 2001.

Ryzhkov, A. B. and Ariya, A.: A theoretical study of the reactions of parent and substituted Criegee intermediates with water and water dimer, Phys. Chem. Chem. Phys., 6, 5042-5050, 2004.

Ryzhkov, A. B. and Ariya, P. A.: The importance of water clusters $\left(\mathrm{H}_{2} \mathrm{O}\right) \mathrm{n}(n=2, \ldots, 4)$ in the reaction of Criegee intermediate with water in the atmosphere, Chem. Phys. Lett., 419, 479-485, 2006.

Sauer, F., Schafer, C., Neeb, P., Horie, O., and Moortgat, G. K.: Formation of hydrogen peroxide in the ozonolysis of isoprene and simple alkenes under humid conditions, Atmos. Environ., 33, 229-241, 1999.

Saunders, S. M., Jenkin, M. E., Derwent, R. G., and Pilling, M. J.: Protocol for the development of the Master Chemical Mechanism, MCM v3 (Part A): tropospheric degradation of nonaromatic volatile organic compounds, Atmos. Chem. Phys., 3, 161-180, doi:10.5194/acp-3-161-2003, 2003.

Seinfeld, J. H. and Pandis, S. N.: Atmospheric Chemistry and Physics: From Air Pollution to Climate Change, second edition, Wiley, New York, p. 288, 2006.

Spittler, M., Barnes, I., Becker, K. H., and Wallington, T. J.: Product study of the $\mathrm{C}_{2} \mathrm{H}_{5} \mathrm{O}_{2}+\mathrm{HO}_{2}$ reaction in 760 torr of air at 284312 K, Chem. Phys. Lett., 321, 57-61, 2000.

Surratt, J. D., Murphy, S. M., Kroll, J. H., Ng, N. L., Hildegrandt, L., Sorooshian, A., Szmigielski, R., Vermeylen, R., Maenhaut, W., Claeys, M., Flagan, R., and Seinfeld, J. H.: Chemical composition of secondary organic aerosol formed from the photooxidation of isoprene, J. Phys. Chem. A., 110, 9665-9690, 2006.
Tobia, H. J. and Ziemann, P. J.: Kinetics of the gas-phase reactions of alcohols, aldehydes, carboxylic acids, and water with the C13 stabilized Criegee intermediate formed from ozonolysis of 1-tetradecene, J. Phys. Chem. A., 105, 6129-6135, 2001.

Vaghjiani, G. L. and Ravishankara, A. R.: Photodissociation of $\mathrm{H}_{2} \mathrm{O}_{2}$ and $\mathrm{CH}_{3} \mathrm{OOH}$ at $248 \mathrm{~nm}$ and $298 \mathrm{~K}$ : Quantum yields for $\mathrm{OH}, \mathrm{O}\left({ }^{3} \mathrm{P}\right)$ and $\mathrm{H}\left({ }^{2} \mathrm{~S}\right)$, J. Chem. Phys., 92, 996-1003, 1990.

Vereecken, L., Harder, H., and Novelli, A.: The reaction of Criegee intermediates with $\mathrm{NO}, \mathrm{RO}_{2}$, and $\mathrm{SO}_{2}$, and their fate in the atmosphere, Phys. Chem. Chem. Phys. 14, 14682-14695, 2012.

Wallington, T. J., and Japar, S. M.: Reaction of $\mathrm{CH}_{3} \mathrm{O}_{2}+\mathrm{HO}_{2}$ in air at $295 \mathrm{~K}$ : A product study, Chem. Phys. Lett., 167, 513-518, 1990.

Wang, H. L., Zhang, X., and Chen, Z. M.: Development of DNPH/HPLC method for the measurement of carbonyl compounds in the aqueous phase: applications to laboratory simulation and field measurement, Environ. Chem., 6, 389-397, 2009.

Wang, H. L., Huang, D., Zhang, X., Zhao, Y., and Chen, Z. M.: Understanding the aqueous phase ozonolysis of isoprene: distinct product distribution and mechanism from the gas phase reaction, Atmos. Chem. Phys., 12, 7187-7198, doi:10.5194/acp-12-71872012, 2012.

Welz, O., Savee, J. D., Osborn, D. L., Vsar, S. S., Percival, C. J., Shallcross, D. E., and Taatjes, C. A.: Direct kinetic measurements of Criegee intermediate $\left(\mathrm{CH}_{2} \mathrm{OO}\right)$ formed by reaction of $\mathrm{CH}_{2} \mathrm{I}$ with $\mathrm{O}_{2}$, Science, 335, 204-207, 2012.

Zhao, R., Lee, A. K. Y., and Abbatt, J. P. D.: Investigation of aqueous-phase photooxidation of glyoxal and methylglyoxal by aerosol chemical ionization mass spectrometry: Observation of hydroxyhydroperoxide formation, J. Phys. Chem. A., 116, 62536263, 2012. 